Article

\title{
Flexible and Electroactive Ionogel Graphene Composite Actuator
}

\author{
Chao Lu ${ }^{1}$ and Xi Chen $1,2, * \mathbb{D}$ \\ 1 Department of Earth and Environmental Engineering, Columbia University, New York, NY 10027, USA; \\ cl3865@columbia.edu \\ 2 School of Chemical Engineering, Northwest University, Xi'an 710069, China \\ * Correspondence: xichen@columbia.edu
}

Received: 19 December 2019; Accepted: 31 January 2020; Published: 1 February 2020

check for updates

\begin{abstract}
Electrochemical actuators have attracted tremendous attention worldwide because of their critical significance to artificial intelligence. The development of electrochemical actuators-with the merits of low driven-voltage, lightweight, flexibility and large deformation-is an urgent task in the development of smart technologies. Nanomaterials with special structures and superior properties provide the opportunity for the development and application of smart actuators. Here, we report an electrochemical actuator based on an ionogel graphene composite, which is assembled with simple casting methodology and can be driven with a low voltage of $2.5 \mathrm{~V}$. The flexible sandwich-structured actuator operates under a capacitive mechanism based on asymmetrical volume expansion of active ions under electrical stimulus. It shows a high specific capacitance of $39 \mathrm{~F} \mathrm{~g}^{-1}$ at current density of $1 \mathrm{~A} \mathrm{~g}^{-1}$ under potential of $2.5 \mathrm{~V}$. The specific capacitance is calculated on the weight of graphene. The device presents a large actuation peak-to-peak displacement of $24 \mathrm{~mm}$ at a frequency of $0.1 \mathrm{~Hz}$ under the stimulus potential of $2.5 \mathrm{~V}$, and it can still reach a large value of $12 \mathrm{~mm}$ at a high frequency of $1 \mathrm{~Hz}$. The free length of the device is $25 \mathrm{~mm}$. Notably, the device exhibits excellent air-working stability at frequency of $1 \mathrm{~Hz}$ under $2.5 \mathrm{~V}$ with the actuation displacement retention of $98 \%$, even after 10,000 cycles. This study presents insights into the design of smart actuators based on nanomaterials, and will accelerate the development of artificial intelligence.
\end{abstract}

Keywords: flexible material; ionogel graphene composite; electroactive actuator

\section{Introduction}

Flexible electrochemical actuators are emerging as promising candidates for applications in smart scenarios-including in virtual reality, the internet of things and soft robotics-and have recently attracted tremendous research enthusiasm worldwide [1-3]. Electrochemical actuators are composed of one polyelectrolyte layer laminated with two electrode layers. MXene is a good candidate electrode material for actuators, because the interlayer spacing of MXene can be changed via the intercalation and de-intercalation of many kinds of ion, such as $\mathrm{K}^{+}, \mathrm{Mg}^{2+}, \mathrm{Na}^{+}$[4]. The development of soft actuators with lightweight, low driven-voltage and large deformation is still kept a challenge, because conventional bulk structural materials, such as noble metals and bulk inorganic materials, cannot address these issues with limited structural properties [5-7]. In addition, aqueous electrolyte-based polyelectrolytes limit the working potential window, and can cause drawback effects and water loss problems when in actuation states [8-10]. Thus, it is urgent to develop high-performance electrochemical actuators with novel, material-based components.

With the rapid development of nanomaterials in recent decades, there now exists a great opportunity for the preparation of high-performance flexible electrochemical actuators based on advanced nanomaterials, such as graphene [11,12], graphitic carbon nitride $[13,14]$, metal-organic 
frameworks [15,16], carbide derived carbon [17], carbon aerogel [18], and other template-synthesized nanomaterials $[19,20]$. These nanomaterials with large surface areas, special electronic structures and highly porous structures are potentially suitable for the fabrication of electrodes. The drawbacks induced by conventional aqueous electrolytes can be avoided using ionogel electrolytes, which are composed with ionic liquid and polymers [21,22]. Ionic liquid-based electrolytes-with the characteristics of a high boiling point, nonflammability, and chemical stability—can effectively prevent the actuators from water loss, solvent effects and drawback effects. Thus, it is a promising strategy to combine advantages of ionogel electrolytes with nanomaterial electrodes for the preparation of next-generation electrochemical actuators.

Here, we report a flexible and electroactive actuator based on graphene materials and ionogel electrolytes, which is fabricated through a simple solution casting method. Other previous works mostly utilized the hot-pressing method, which required sophisticated equipment and precise control of conditions [23-25]. Graphene is selected because of its high electronic conductivity, large surface area and porous structures, which can facilitate electron and ion transfer during actuation processes. A polyvinylidene fluoride/1-ethyl-3-methylimidazolium tetrafluoroborate ( $\left.\mathrm{PVdF} / \mathrm{EMIBF}_{4}\right)$ ionogel electrolyte was applied for its high ionic conductivity and wide potential window. The actuator shows the high specific capacitance of $39 \mathrm{~F} \mathrm{~g}^{-1}$ at current density of $1 \mathrm{~A} \mathrm{~g}^{-1}$ under potential of $2.5 \mathrm{~V}$, indicating its high accommodation for active ions. The driven voltage of the actuator is only as low as $2.5 \mathrm{~V}$, which is easily achievable using the dry batteries used in everyday life and thus presents great potential for artificial intelligence applications. The device also displays a large actuation displacement of $24 \mathrm{~mm}$ at frequency of $0.1 \mathrm{~Hz}$ under $2.5 \mathrm{~V}$, and the displacement retains as high as $12 \mathrm{~mm}$ at higher frequency of $1 \mathrm{~Hz}$. It is found that the actuator shows excellent cycling stability with high displacement retention of $98 \%$, even over 10000 cycles at $1 \mathrm{~Hz}$ under $2.5 \mathrm{~V}$. This study provides a promising strategy for the fabrication of high-performance flexible electrochemical actuators, and will also shed light on the design of other flexible electrochemical devices.

\section{Materials and Methods}

\subsection{Materials}

PVdF polymer and DMF (Dimethyl Formamide) solvent were obtained from Sinopharm Chemical Reagent Co., Ltd., (Shanghai, China). $\mathrm{EMIBF}_{4}$ was purchased from Millipore Sigma company (New York City, NY, USA). Graphene powder (NO: XFGNP009) was obtained from XFNANO Materials Tech Co., Ltd., (Nanjing, Jiangsu, China)

\subsection{Synthesis of Ionogel Electrolyte}

Firstly, $1.0 \mathrm{~g}$ PVdF and $1.5 \mathrm{~g} \mathrm{EMIBF} 4$ were mixed in $30 \mathrm{~mL}$ DMF solvent at $30^{\circ} \mathrm{C}$. Then, the solution was poured into a mould and kept at $80^{\circ} \mathrm{C}$ for $24 \mathrm{~h}$. Finally, the $\mathrm{PVdF} / \mathrm{EMIBF}_{4}$ electrolyte membrane was obtained by peeling off the mould after vacuum drying at $80^{\circ} \mathrm{C}$ for $12 \mathrm{~h}$.

\subsection{Fabrication of Ionogel Graphene Composite Actuator}

Firstly, $50 \mathrm{mg}$ graphene powder and $5 \mathrm{mg}$ PVdF were dispersed in $10 \mathrm{~mL}$ DMF for $1 \mathrm{~h}$ through horn sonication in ice bath. Subsequently, the suspension was cast onto one side of $\mathrm{PVdF} / \mathrm{EMIBF}_{4}$ electrolyte and then dried at $80^{\circ} \mathrm{C}$ for $12 \mathrm{~h}$. Following that, the actuator was obtained by casting the other side with graphene electrode with same method. The thickness of the actuator is $117 \mu \mathrm{m}$.

\subsection{Characterizations}

SEM and TEM images were made with Hitachi S-4800 (New York City, NY, USA) and FEI Tecnai F200 (New York City, NY, USA), respectively. Electrochemical performances of ionic actuator were measured with Bio-logic Potentiostat VMP3 work station (Bio-Logic, Seyssinet-Pariset, France). The CV curve was measured in the potential range of $0-2.5 \mathrm{~V}$ with scan rate of $100 \mathrm{mV} \mathrm{s}^{-1}$. Electrochemical 
impedance spectroscopy was conducted from $10 \mathrm{mHz}$ to $100 \mathrm{kHz}$ with a voltage amplitude of $10 \mathrm{mV}$. Charge-discharge curve was conducted at $1 \mathrm{~A} \mathrm{~g}^{-1}$ under voltage of $2.5 \mathrm{~V}$. The displacement of actuator was measured by Keyence LK-G800 laser positioning equipment (Keyence company, Osaka, Japan).

\section{Results and Discussion}

The mechanism and sandwich structure of ionogel graphene composite actuator are briefly illustrated in Figure 1. Typically, cations and anions migrate and insert into cathode and anode, respectively, under an applied electrical field. The insertion of ions induces the expansion of electrodes, because the layer distance of graphene enlarges with inserted ions. The cations and anions in ionogel electrolytes have different sizes, and thus will induce the asymmetric expansion of cathode and anode, which directly cause deformation of electrochemical actuators $[5,25]$. The as-described mechanism is based on a capacitive mechanism, and the actuation effect is mainly affected by accommodated ions in the electrodes. Nanomaterials with porous structures are promising for achieving large deformation in actuators.

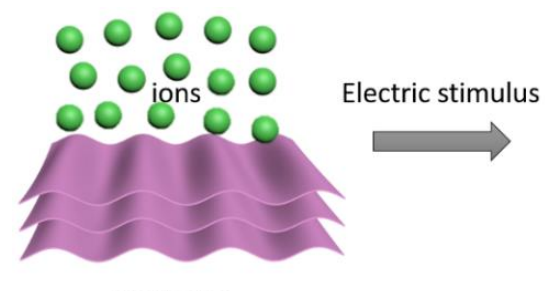

Graphene

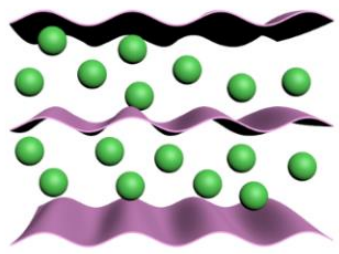

Ion insertion

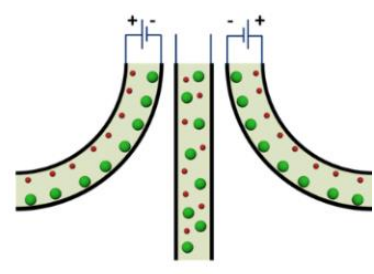

Actuator

Figure 1. Schematic for mechanism of ionogel graphene composite actuator.

The morphology of graphene materials is presented in Figure 2, which has been investigated with scanning electron microscopy (SEM) and transmission electron microscopy (TEM) techniques. The SEM images in Figure 2a,b clearly verify the porous structure of graphene materials, which is favorable for accommodation of active ions migrated into electrodes. The TEM image in Figure $2 c$ shows the typical two-dimensional layered structure of graphene materials. In the XRD spectra, the characteristic peak at around $25^{\circ}$ is attributed to (002) diffraction of graphene. In the raman spectra, the peaks at 1350 and $1582 \mathrm{~cm}^{-1}$ are attributed to D (disordered and defective structure) and G (graphitic structure) bands of graphene. The XPS C 1 s spectra can be fitted into three peaks, which are attributed to characterize the peaks of $\mathrm{C}-\mathrm{C}, \mathrm{C}=\mathrm{C}$ and $\mathrm{C}-\mathrm{O}$. As illustrated by the scheme in Figure 1, the two-dimensional structure can promote ion immigration under an electrical field through the formation of layered ion channels for fast orientation transfer. In order to verify the potential of graphene materials for electrochemical actuators, a flexible actuator has been fabricated utilizing graphene materials as electrodes, and ionogel $\mathrm{PVdF} / \mathrm{EMIBF}_{4}$ as an electrolyte. The electrochemical impedance spectroscopy (EIS) result is shown in Figure $3 a$, and it was found that the equivalent series resistance is only $19 \Omega$, which indicates good internal contact in the actuator. The cyclic voltammetry (CV) curve in Figure $3 \mathrm{~b}$ displays a regular rectangle shape with the typical capacitive behavior of ion storage. The charge-discharge (CD) curve of the actuator at a current density of $1 \mathrm{~A} \mathrm{~g}^{-1}$ under a potential of $2.5 \mathrm{~V}$ is shown in Figure 3c. The near triangle shape of the curve verifies the high coulombic efficiency of the device under charge and discharge states, which is believed to promote electro-mechanical energy conversion in actuator. 

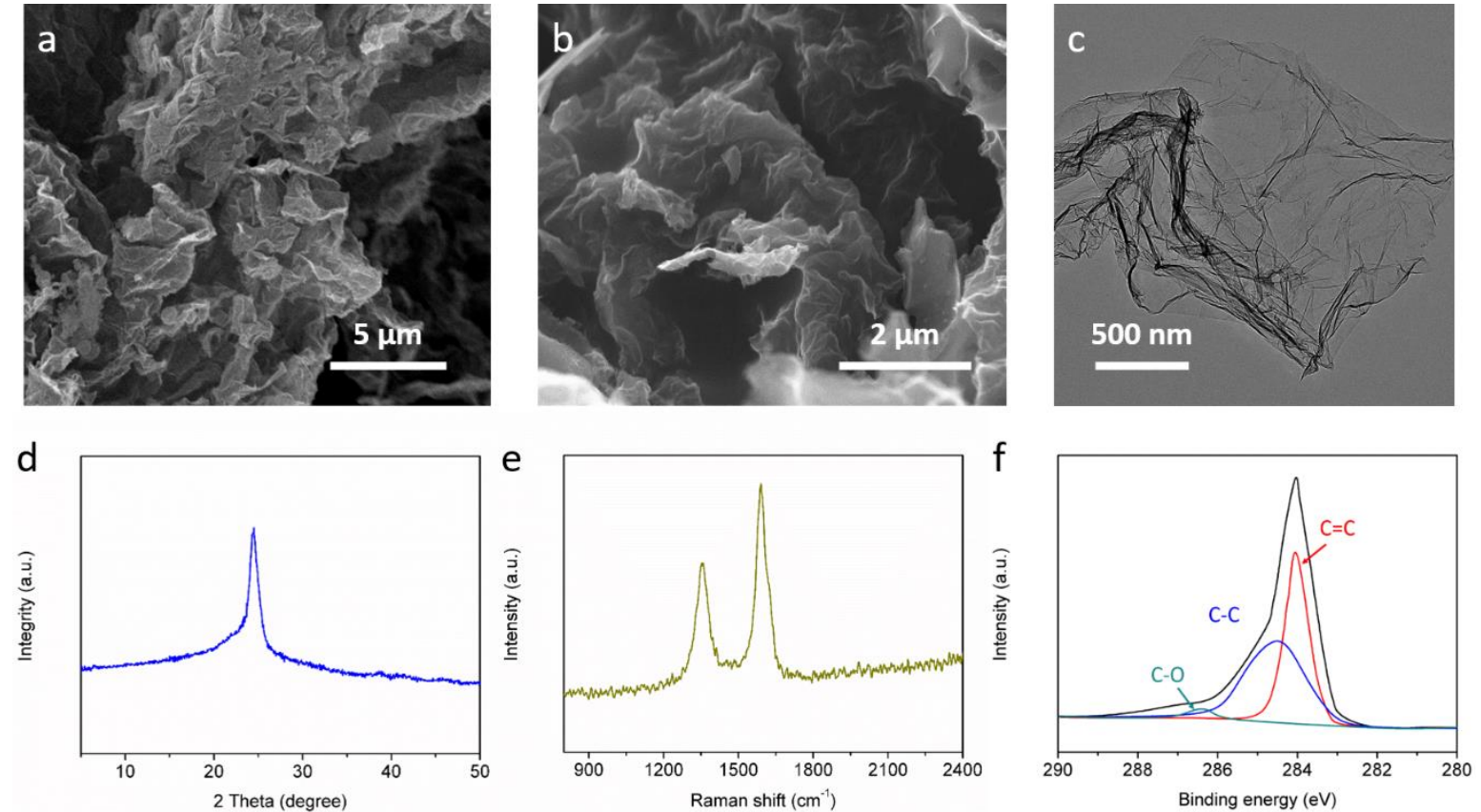

Figure 2. SEM (a,b) and TEM images (c) of graphene materials. (d-f) XRD, Raman and XPS spectras.
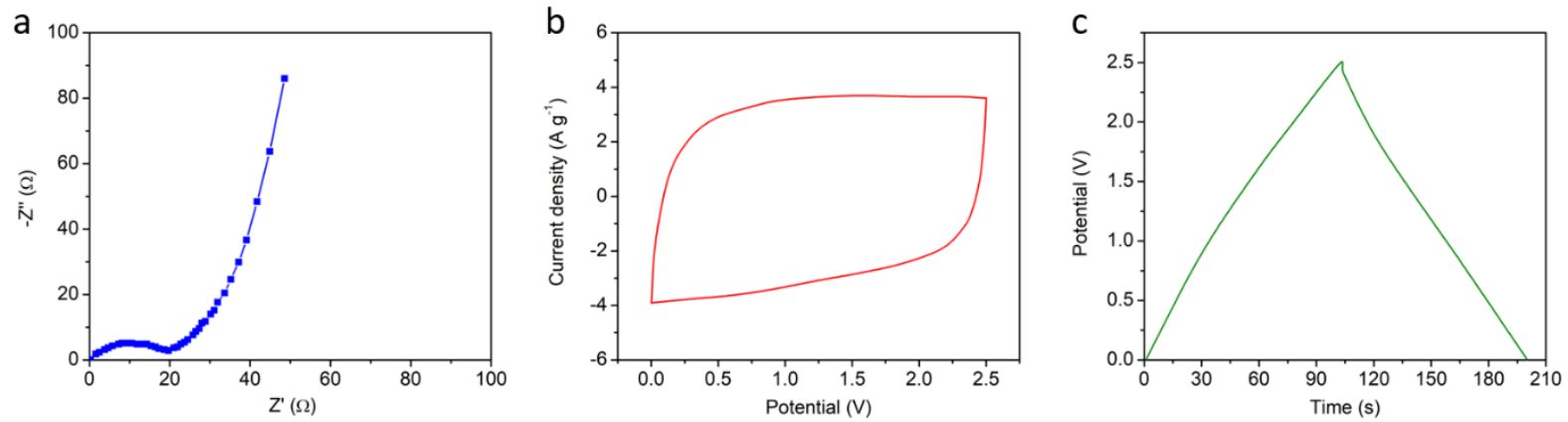

Figure 3. Electrochemical impedance spectroscopy spectra (a) of the actuator. Cyclic voltammetry curve (b) of the device at scan rate of $100 \mathrm{mV} \mathrm{s}^{-1}$. Charge-discharge curve (c) of the device at current density of $1 \mathrm{~A} \mathrm{~g}^{-1}$.

The flexible bimorph cantilever actuator is evaluated through multi-step voltage stimulus in Figure 4a. The deformation direction of the actuator can be precisely controlled by changing the electric property of the applied voltages. The actuator presents large actuation displacement of $24 \mathrm{~mm}$ at a frequency of $0.1 \mathrm{~Hz}$ under a potential of $2.5 \mathrm{~V}$ and operates stably in the first few cycles, as shown in Figure 4b. The actuation amplitude of the device can be adjusted through the control of applied frequencies. As displayed in Figure 4c, the displacement of the actuator decreases from $24 \mathrm{~mm}$ to 12 $\mathrm{mm}$ when the frequency increases from $0.1 \mathrm{~Hz}$ to $1 \mathrm{~Hz}$. Even the frequency increases to a high level, the device also shows a negligible response time and keeps a high actuation deformation. As the cycling life of actuators is critical to their practical application, the cycling stability of an actuator has been evaluated at frequency of $1 \mathrm{~Hz}$ under potential of $2.5 \mathrm{~V}$ in Figure $4 \mathrm{~d}$. It is worth mentioning that the device shows excellent cycling performance with displacement retention as high as $98 \%$, even after 10,000 actuation cycles. Compared with conventional noble metal electrode-based actuators, the graphene-based actuator in this study shows better cycling performances $[5,26]$. This is because noble metal electrodes usually have bulky and dense structures, which are easy to degrade under repeated working cycles. As a cross-section of the composite is important, we provide the cross-section SEM image of the actuator in the inset of Figure $4 \mathrm{~d}$. It is found that there is a tight coupling interface 
between the electrode and electrolyte layers, which guarantees the stable actuation performances of the device. The large and controllable actuation performance of this electrochemical actuator is a significant achievement in the smart actuation field, and should somewhat accelerate the development of artificial intelligence.
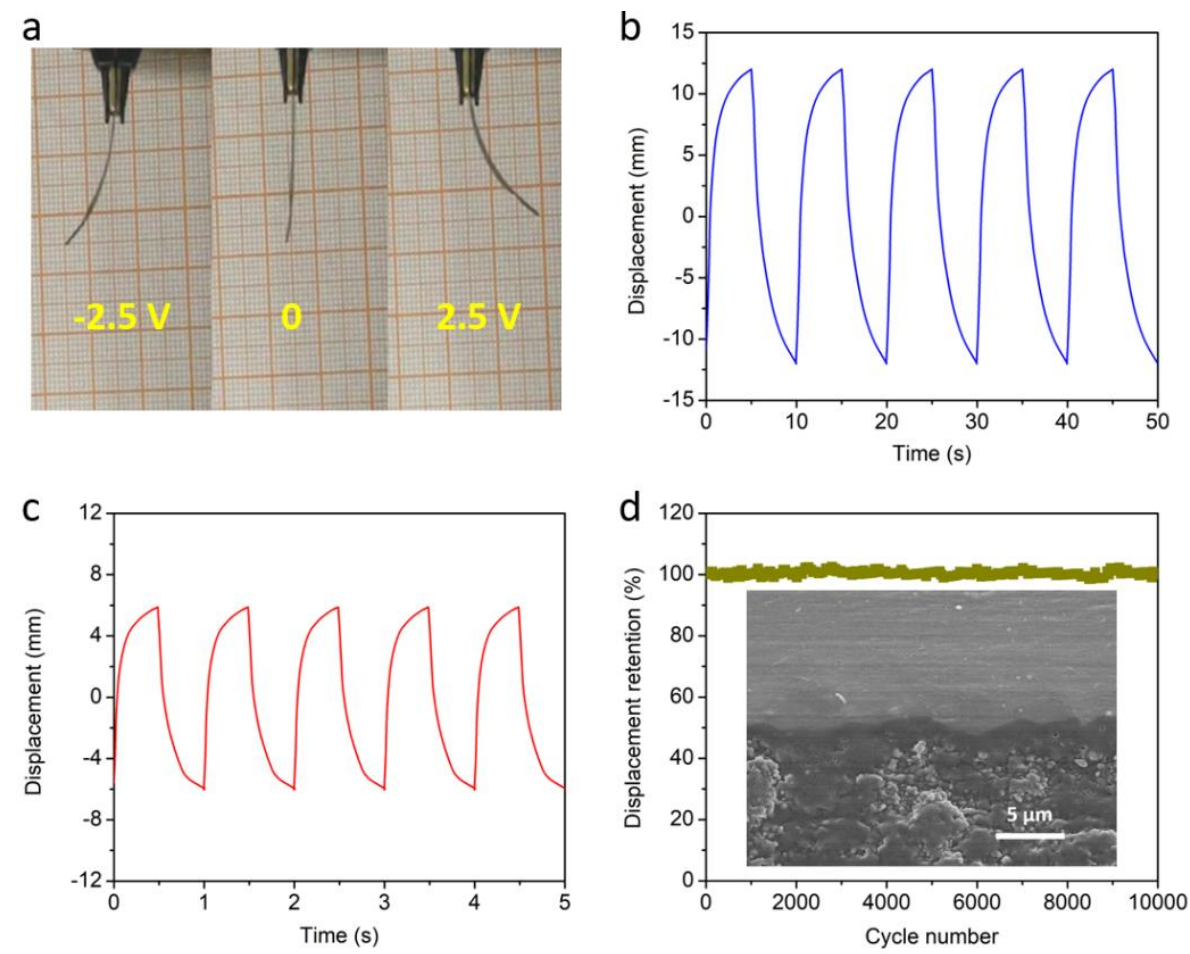

Figure 4. Optical images (a) of actuator under actuation states. Actuation displacements of actuator under potential of $2.5 \mathrm{~V}$ at frequencies of $0.1 \mathrm{~Hz}(\mathbf{b})$ and $1 \mathrm{~Hz}(\mathbf{c})$, respectively. Cycling stability of actuator (d) under potential of $2.5 \mathrm{~V}$ at frequency of $1 \mathrm{~Hz}$ over 10000 cycles. Inset is cross-section SEM image of device.

\section{Conclusions}

In summary, a flexible and electroactive ionogel graphene composite actuator has been prepared based on graphene electrodes and ionogel electrolytes through a simple solution casting method. The porous structure of graphene facilitates the accommodation of active ions, and the chemically stable ionogel electrolyte promotes the cycling performances of the device. The as-prepared actuator displays a high specific capacity of $39 \mathrm{~F} \mathrm{~g}^{-1}$ at a current density of $1 \mathrm{~A} \mathrm{a}^{-1}$, under a voltage of $2.5 \mathrm{~V}$. Moreover, the actuator can operate under a low driven voltage of $2.5 \mathrm{~V}$, which can be easily realized using the dry batteries used in everyday life. It shows large deformations both at high and low actuation frequencies, and the deformation amplitude and direction can be adjusted by controlling the driven voltages. In addition, the device displays excellent cycling stability, with actuation retention of $98 \%$ over 10,000 cycles in an air atmosphere, indicating promising practical applications. The research conducted in designing in this work will provide insights for the design of other flexible electrochemical devices with long cycling lives.

Author Contributions: Conceptualization, C.L. and X.C.; methodology, C.L.; investigation, C.L.; resources, X.C.; data curation, C.L. and X.C.; writing-original draft preparation, C.L.; writing-review and editing, X.C.; visualization, C.L. All authors have read and agreed to the published version of the manuscript.

Funding: This research received no external funding.

Acknowledgments: This work was supported by the Earth Engineering Center, and Center for Advanced Materials for Energy and Environment at Columbia University. 
Conflicts of Interest: The authors declare no conflict of interest.

\section{References}

1. Gong, J.; Lin, H.; Dunlop, J.W.C.; Yuan, J. Hierarchically arranged helical fiber actuators derived from commercial cloth. Adv. Mater. 2017, 29, 1605103. [CrossRef] [PubMed]

2. Lu, C.; Yang, Y.; Wang, J.; Fu, R.; Zhao, X.; Zhao, L.; Ming, Y.; Hu, Y.; Lin, H.; Tao, X.; et al. High-performance graphdiyne-based electrochemical actuators. Nat. Commun. 2018, 9, 752. [CrossRef] [PubMed]

3. Liu, D.; Tarakanova, A.; Hsu, C.C.; Yu, M.; Zheng, S.; Yu, L.; Liu, J.; He, Y.; Dunstan, D.J.; Buehler, M.J. Spider dragline silk as torsional actuator driven by humidity. Sci. Adv. 2019, 5, eaau9183. [CrossRef] [PubMed]

4. Umrao, S.; Tabassian, R.; Kim, J.; Nguyen, V.H.; Zhou, Q.; Nam, S.; Oh, I.-K. MXene artificial muscles based on ionically cross-linked $\mathrm{Ti}_{3} \mathrm{C}_{2} \mathrm{~T}_{x}$ electrode for kinetic soft robotics. Sci. Rob. 2019, 4, eaaw7797. [CrossRef]

5. Kong, L.; Chen, W. Carbon nanotube and graphene-based bioinspired electrochemical actuators. Adv. Mater. 2014, 26, 1025-1043. [CrossRef]

6. Shahinpoory, M.; Bar-Cohenz, Y.; Simpsonx, J.O.; Smithx, J. Ionic polymer-metal composites (IPMCs) as biomimetic sensors, actuators and artificial muscles-A review. Smart Mater. Struct. 1998, 7, 15-30. [CrossRef]

7. Lee, J.A.; Li, N.; Haines, C.S.; Kim, K.J.; Lepro, X.; Ovalle-Robles, R.; Kim, S.J.; Baughman, R.H. Electrochemically powered, energy-conserving carbon nanotube artificial muscles. Adv. Mater. 2017, 29, 1700870. [CrossRef]

8. Shao, L.-H.; Biener, J.; Jin, H.-J.; Biener, M.M.; Baumann, T.F.; Weissmüller, J. Electrically tunable nanoporous carbon hybrid actuators. Adv. Funct. Mater. 2012, 22, 3029-3034. [CrossRef]

9. Fukushima, T.; Asaka, K.; Kosaka, A.; Aida, T. Fully plastic actuator through layer-by-layer casting with ionic-liquid-based bucky gel. Angew. Chem. Int. Ed. Engl. 2005, 44, 2410-2413. [CrossRef]

10. Kim, O.; Kim, S.J.; Park, M.J. Low-voltage-driven soft actuators. Chem. Commun. 2018, 54, 4895-4904. [CrossRef]

11. Lu, C.; Chen, X. In situ synthesized PEO/NBR composite ionogels for high-performance all-solid-state supercapacitors. Chem. Commun. 2019, 55, 8470-8473. [CrossRef]

12. Huang, X.; Zeng, Z.; Fan, Z.; Liu, J.; Zhang, H. Graphene-based electrodes. Adv. Mater. 2012, $24,5979-6004$. [CrossRef]

13. Lu, C.; Yang, Y.; Chen, X. Ultrathin conductive graphitic carbon nitride assembly through van der Waals epitaxy toward high energy-density flexible supercapacitors. Nano Lett. 2019, 19, 4103-4111. [CrossRef]

14. Groenewolt, M.; Antonietti, M. Synthesis of $\mathrm{g}-\mathrm{C}_{3} \mathrm{~N}_{4}$ nanoparticles in mesoporous silica host matrices. Adv. Mater. 2005, 17, 1789-1792. [CrossRef]

15. Lu, C.; Chen, X. Sea-island nanostructured polyvinylidene fluoride/zeolitic imidazolate framework-8 polyelectrolyte for high-performance all-solid-state supercapacitors. J. Power Sources 2020, 448, 227587. [CrossRef]

16. Li, W.H.; Ding, K.; Tian, H.R.; Yao, M.S.; Nath, B.; Deng, W.H.; Wang, Y.; Xu, G. Conductive metal-organic framework nanowire array electrodes for high-performance solid-state supercapacitors. Adv. Funct. Mater. 2017, 27, 1702067. [CrossRef]

17. Kaasik, F.; Must, I.; Baranova, I.; Põldsalu, I.; Lust, E.; Johanson, U.; Punning, A.; Aabloo, A. Scalable fabrication of ionic and capacitive laminate actuators for soft robotics. Sens. Actuators B 2017, 246, 154-163. [CrossRef]

18. Palmre, V.; Lust, E.; Jänes, A.; Koel, M.; Peikolainen, A.-L.; Torop, J.; Johanson, U.; Aabloo, A. Electroactive polymer actuators with carbon aerogel electrodes. J. Mater. Chem. 2011, 21, 2577-2583. [CrossRef]

19. Lu, C.; Wang, D.; Zhao, J.; Han, S.; Chen, W. A continuous carbon nitride polyhedron assembly for high-performance flexible supercapacitors. Adv. Funct. Mater. 2017, 27, 1606219. [CrossRef]

20. Li, H.; Li, X.; Liang, J.; Chen, Y. Hydrous $\mathrm{RuO}_{2}$-decorated mxene coordinating with silver nanowire inks enabling fully printed micro-supercapacitors with extraordinary volumetric performance. Adv. Energy Mater. 2019, 9, 1803987. [CrossRef]

21. Lu, C.; Chen, X. An interfacial polymerization strategy towards high-performance flexible supercapacitors. J. Mater. Chem. A 2019, 7, 20158-20161. [CrossRef]

22. Le Bideau, J.; Viau, L.; Vioux, A. Ionogels, ionic liquid based hybrid materials. Chem. Soc. Rev. 2011, 40, 907-925. [CrossRef] [PubMed] 
23. Lu, L.; Liu, J.; Hu, Y.; Zhang, Y.; Randriamahazaka, H.; Chen, W. Highly stable air working bimorph actuator based on a graphene nanosheet/carbon nanotube hybrid electrode. Adv. Mater. 2012, 24, 4317-4321. [CrossRef] [PubMed]

24. Chen, I.P.; Yang, M.C.; Yang, C.H.; Zhong, D.X.; Hsu, M.C.; Chen, Y. Newton output blocking force under low-voltage stimulation for carbon nanotube-electroactive polymer composite artificial muscles. ACS Appl. Mater. Interfaces 2017, 9, 5550-5555. [CrossRef]

25. Wu, G.; Hu, Y.; Liu, Y.; Zhao, J.; Chen, X.; Whoehling, V.; Plesse, C.; Nguyen, G.T.; Vidal, F.; Chen, W. Graphitic carbon nitride nanosheet electrode-based high-performance ionic actuator. Nat. Commun. 2015, 6, 7258. [CrossRef]

26. Jung, K.; Nam, J.; Choi, H. Investigations on actuation characteristics of IPMC artificial muscle actuator. Sens. Actuators A Phys. 2003, 107, 183-192. [CrossRef]

(C) 2020 by the authors. Licensee MDPI, Basel, Switzerland. This article is an open access article distributed under the terms and conditions of the Creative Commons Attribution (CC BY) license (http://creativecommons.org/licenses/by/4.0/). 